Document downloaded from:

http://hdl.handle.net/10251/37849

This paper must be cited as:

Gotor Candel, RJ.; Royo Calvo, S.; Costero Nieto, AM.; Gil Grau, S.; Parra Alvarez, M.; Martínez Mañez, R.; Sancenón Galarza, F. (2012). Nerve agent simulant detection by using chromogenic triaryl methane cation probes. Tetrahedron. 68(41):8612-8616. doi:10.1016/j.tet.2012.07.091.

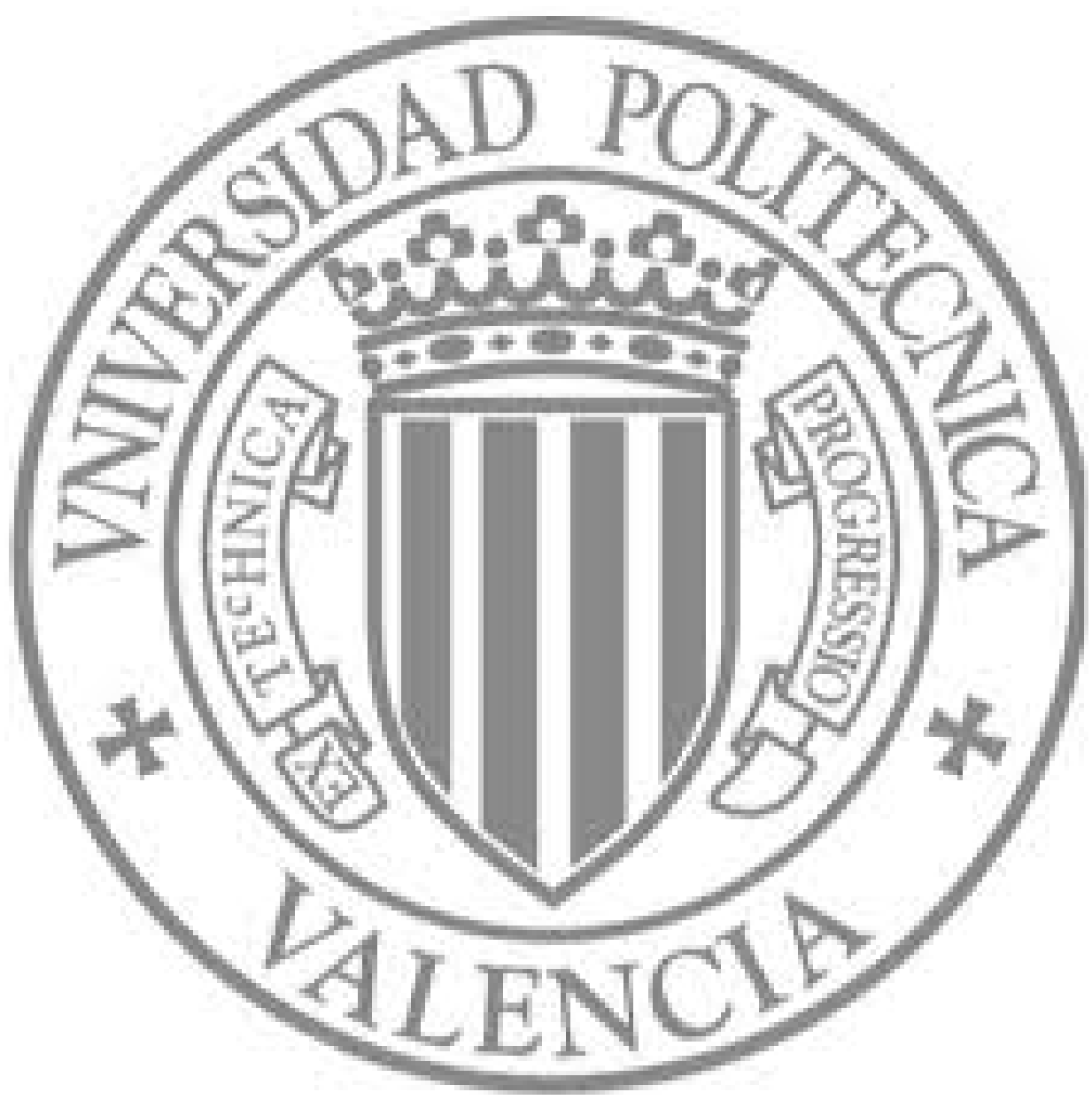

The final publication is available at

http://dx.doi.org/10.1016/j.tet.2012.07.091

Copyright Elsevier 


\section{Graphical Abstract}

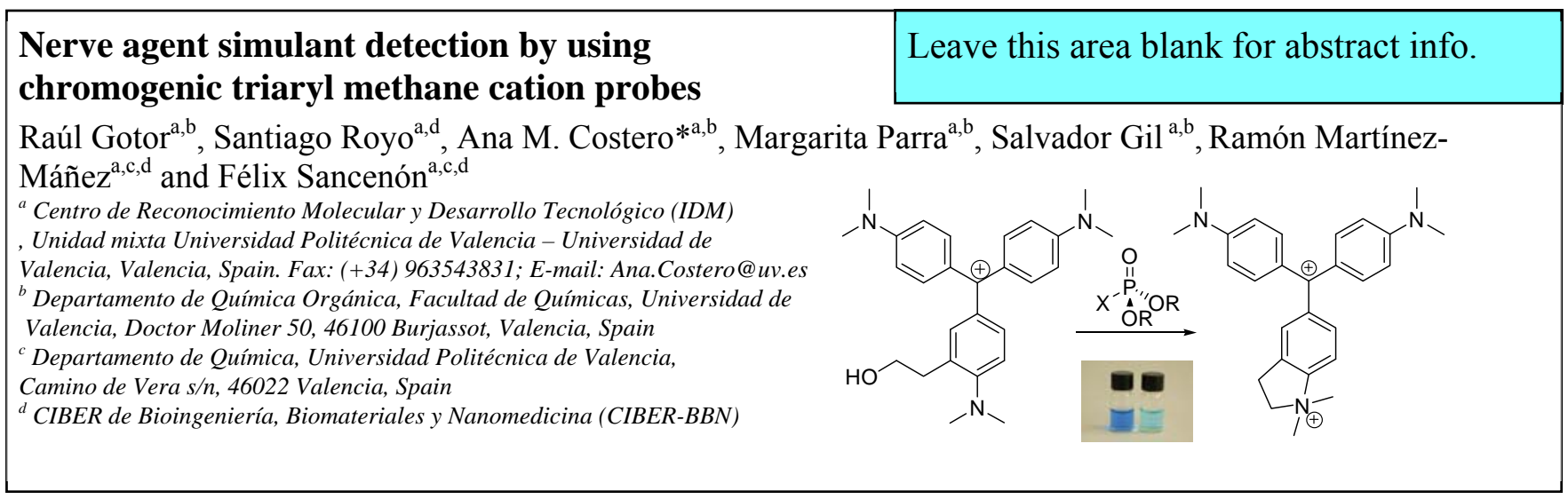




\title{
Nerve agent simulant detection by using chromogenic triaryl methane cation probes
}

\author{
Raúl Gotor ${ }^{\mathrm{a}, \mathrm{b}}$, Santiago Royo ${ }^{\mathrm{a}, \mathrm{d}}$, Ana M. Costero*a,b, Margarita Parra ${ }^{\mathrm{a}, \mathrm{b}}$, Salvador Gil ${ }^{\mathrm{a}, \mathrm{b}}$, Ramón Martínez- \\ Máñez ${ }^{\mathrm{a}, \mathrm{c}, \mathrm{d}}$ and Félix Sancenón ${ }^{\mathrm{a}, \mathrm{c}, \mathrm{d}}$ \\ ${ }^{a}$ Centro de Reconocimiento Molecular y Desarrollo Tecnológico (IDM), Unidad mixta Universidad Politécnica de Valencia - Universidad de Valencia, \\ Valencia, Spain. Fax: (+34) 963543831; E-mail: Ana.Costero@uv.es \\ ${ }^{b}$ Departamento de Química Orgánica, Facultad de Químicas, Universidad de Valencia, Doctor Moliner 50, 46100 Burjassot, Valencia, Spain \\ c Departamento de Química, Universidad Politécnica de Valencia, Camino de Vera s/n, 46022 Valencia, Spain \\ ${ }^{d}$ CIBER de Bioingeniería, Biomateriales y Nanomedicina (CIBER-BBN)
}

\section{Introduction}

Many Nerve agents are highly toxic phosphoric acid esters, and are structurally related to the organophosphates family. These compounds have rapid, severe effects on human and animal health when used in gas, aerosol or liquid. The effects of nerve agents are mainly due to their ability to inhibit the action of acetylcholinesterase, a critical central nervous system enzyme. ${ }^{1}$ Nerve agents are considered to be among the most dangerous chemical warfare agents (CWAs). ${ }^{2}$ In addition, their easy production, their extreme toxicity and their possible use in terrorist attacks, emphasize the need to detect these odourless and colourless chemicals via the development of reliable and accurate methods. ${ }^{3,4}$ Current protocols for monitoring nerve agents are based on the use of biosensors, ${ }^{5,6}$ ion mobility spectroscopy $(\mathrm{IMS}){ }^{7}$ electrochemistry, ${ }^{8,9}$ microcantilevers, ${ }^{10,11}$ photonic crystals, ${ }^{12,13}$ optical-fibre arrays, ${ }^{14}$ etc. As an alternative to these, the development of easy-to-use fluorogenic and chromogenic probes has proved useful for signalling these derivatives in different media and has kindled interest in recent years. ${ }^{415-19}$ Moreover, colorimetric sensing is particularly attractive as it requires low-cost widely used instrumentation, and also offers the possibility of detecting these target analytes "to the naked eye".

We have recently shown an interest in developing chemical probes capable of signalling the presence of nerve agent simulants following different sensing paradigms. ${ }^{20,21}$ Moreover, given the high toxicity of nerve agents Sarin, Soman and Tabun, the related compounds DCP and DCNP have been typically used as models for the design of indicators and sensing systems as they have a similar reactivity, but lack severe toxicity (Figure 1).

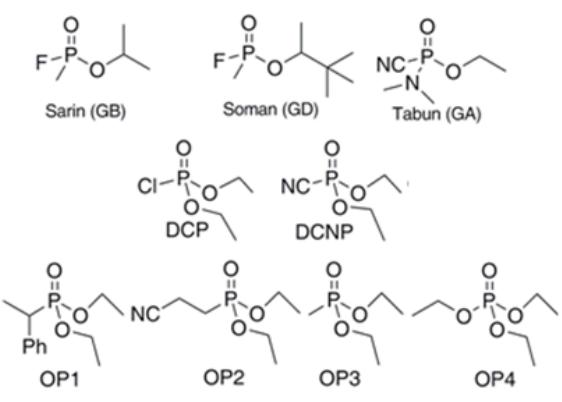

Figure 1: Nerve agents and simulants
To design the probes, we followed the well-established paradigm that relies on the use of dyes containing suitable reactive sites which, upon reaction with target guests, result in a colorimetric event. The use of specific reactions to generate the observable changes ensures the selectivity of chemodosimeters. In addition, the adequate election of the dyes gives rise to probes that shows high sensitivity. Probably, the most common chemical reaction involving nerve agents takes place directly at the phosphorus atom; in fact, the P-X bond is easily broken by nucleophiles such as water or hydroxyl ions. Given the versatility of this approach, we designed chromogenic probes $\mathbf{1}$ and $\mathbf{2}$ (see Figure 2), whose structures contain nucleophilic moieties (able to react with nerve agents) connecting triaryl methane cations dyes.
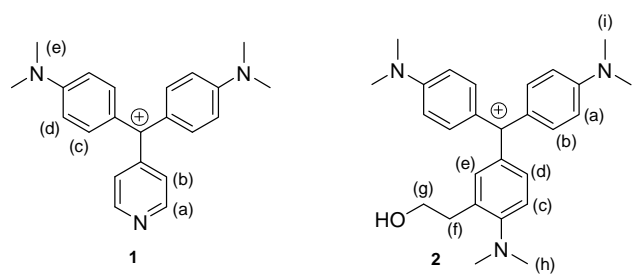

Figure 2: Chromogenic triaryl methane cations

Triaryl methane cations dyes present the advantage of being more stables when they are compared with the triarylcarbinol compounds previously used in our laboratory. In fact, triarylcarbinol derivatives can be dehydrated in a very small yield under many different conditions giving rise to colour changes in the sensor when solutions are kept for long times.

\section{Results and discussion}

Compound $\mathbf{1}$ is the well-known 4-Pyridine Green cation and 2 is a modification of the Crystal Violet dye whose structure contains an additional 2-hydroxyethyl moiety. The former contains a pyridine group capable of undergoing phosphorylation reactions. The latter holds a 2-(2-(dimethylamino)phenyl)ethanol moiety (see Scheme 1), which is known to give reactions with phosphonate substrates to further undergo rapid intramolecular $N$-alkylation to yield a quaternary ammonium salt. ${ }^{20-22} \mathrm{We}$ expected, upon reaction with certain organophosphorous (OP) substrates, the transformation of pyridine $\mathbf{1}$ into the corresponding pyridinium salt. The stronger electron withdrawing character of the pyridinium salt would result in a modulation of the push-pull character on the dye and in a colour shift. Similarly the phosphorilation of the hydroxyl group in compound 2 that is followed by an intramolecular $\mathrm{S}_{\mathrm{N}} 2$ reaction would transform the tertiary amine into a quaternary ammonium salt with similar changes that these described for compound $\mathbf{1}$. 
<smiles>CCN(C)c1ccc(C(=O)c2ccc(N(C)C)cc2)cc1CCO</smiles>

Scheme 1: Synthesis of cromoreagent 2

\section{Detection studies}

First, reactivity of $\mathbf{1}$ and $\mathbf{2}$ was tested with DCP and DCNP (see Scheme 2) in acetonitrile: water $(25: 75 \mathrm{v} / \mathrm{v})$ buffered at $\mathrm{pH}$ 5.5 with MES (2-morpholinoethanesulfonic acid) $0.1 \mathrm{~mol} \mathrm{dm}^{-3}$. These conditions were chosen for two reasons: (i) to guaranty that the observed changes were due to the expected reaction and not to a mere acid-base process and (ii) to ensure the probe solubility.

In this medium, compound $\mathbf{1}$ displays an intense absorption band at $635 \mathrm{~nm}$, typical of triarylcations. Addition of either DCP or DCNP resulted in a bathochromic shift of $20 \mathrm{~nm}$. This change in colour is consistent with the phosphorylation of the pyridine, and gives rise to a pyridinium salt showing a stronger electron withdrawing character (when compared with pyridine) ${ }^{23,26}$ (see Figure 2). In order to assess the proposed mechanism, ${ }^{1} \mathrm{H}$ NMR studies were carried out. Addition of DCNP to the $\mathrm{CD}_{3} \mathrm{CN}$ solutions of chromoreagent 1 induced clear changes in the ${ }^{1} \mathrm{H}$ NMR spectrum. Thus, $\mathrm{H}_{\mathrm{b}}$ underwent a downfield shift of $\Delta \delta=$ $0.13 \mathrm{ppm}$, whereas the variation of the $\mathrm{H}_{\mathrm{a}}$ shifts was almost negligible. In the dimethylaniline ring, $\mathrm{H}_{\mathrm{c}}$ and $\mathrm{H}_{\mathrm{d}}$ were downfield shifted $(\Delta \delta=0.03 \mathrm{ppm}$ and $\Delta \delta=0.02 \mathrm{ppm}$ respectively). The signals corresponding to the methyl groups underwent no chemical shift variation (Figure 3 ). The changes observed were in agreement with the proposed formulation.
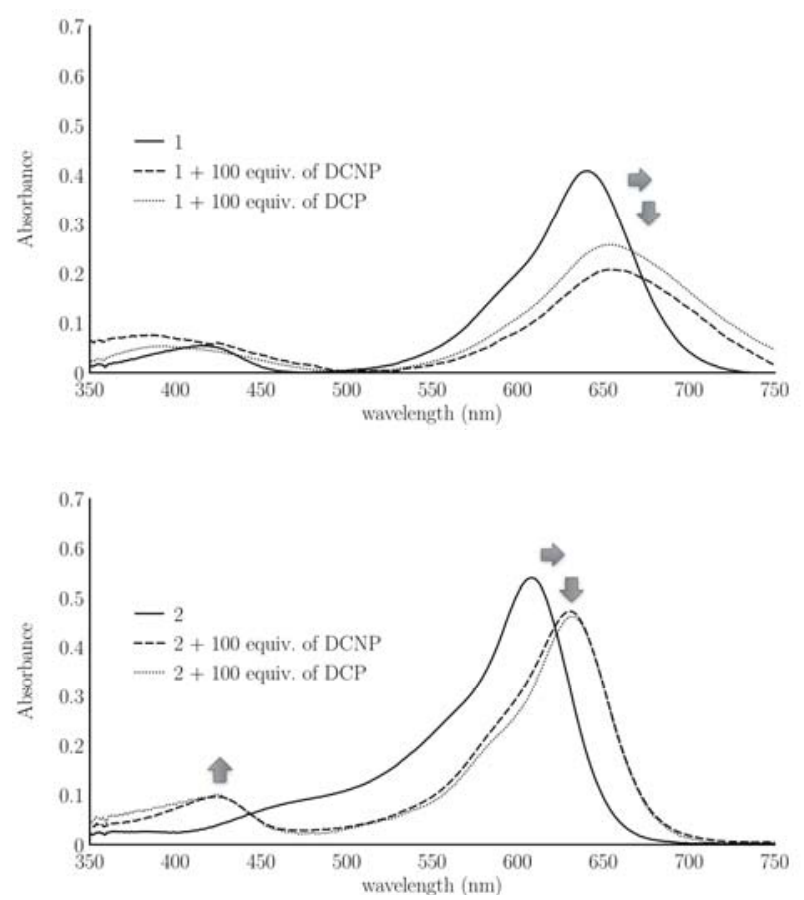

Figure 3: (up) UV spectrum of $1\left(1 \times 10^{-5} \mathrm{~mol} \mathrm{dm}^{-3}\right.$ in buffered acetonitrile:water $(25: 75 \mathrm{v} / \mathrm{v})$ solutions $(\mathrm{pH} \mathrm{5.5,} \mathrm{MES} 0.1 \mathrm{~mol}$ $\left.\mathrm{dm}^{-3}\right)$ ) free and upon addition of 100 equiv of DCNP and DCP; (bottom) UV spectrum of $2\left(1 \times 10^{-5} \mathrm{~mol} \mathrm{dm}^{-3}\right.$ in buffered acetonitrile:water $(25: 75 \mathrm{v} / \mathrm{v})$ solutions $(\mathrm{pH} 5.5$, MES $0.1 \mathrm{~mol}$ $\left.\mathrm{dm}^{-3}\right)$ ) free and upon addition of 100 equiv of DCNP and DCP.
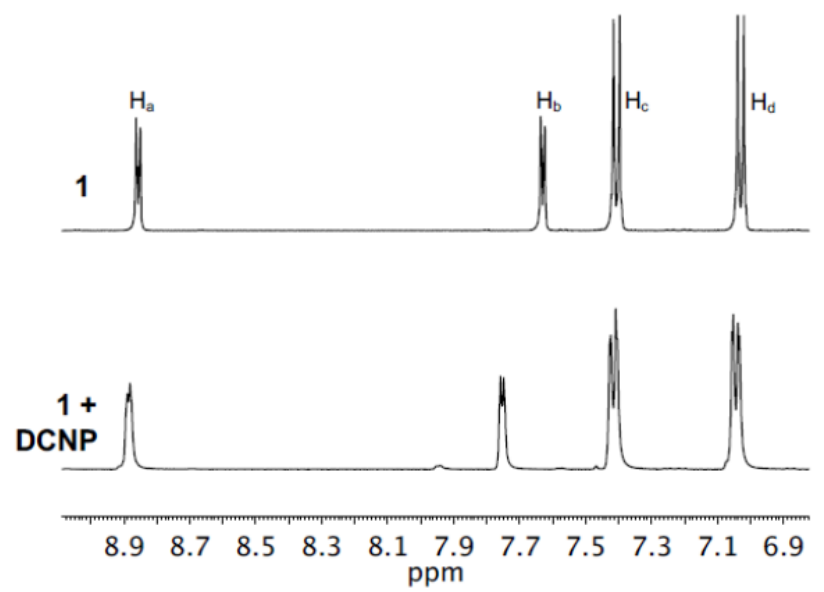

Figure 4. ${ }^{1} \mathrm{H}$ NMR spectra of ligand 1: free and in the presence of 36 equiv. of DCNP (aromatic region)

Compound $2\left(1 \times 10^{-5} \mathrm{~mol} \mathrm{dm}^{-3}\right.$ in acetonitrile:water $(25: 75)$ buffered at $\mathrm{pH} 5.5$ using MES $0.1 \mathrm{~mol} \mathrm{dm}^{-3}$ ) showed an absorption band at $603 \mathrm{~nm}$, which underwent a bathochromic shift at $627 \mathrm{~nm}$, along with the appearance of a new band at 427 nm upon addition of DCNP or DCP (Figure 2). This colour modulation from marine blue to turquoise (see Figure 5) was consistent with the intramolecular cyclisation process in which the donor character of $N, N$-dimethylanilino moiety drastically diminished upon the formation of the corresponding quaternary ammonium salt (scheme 2).
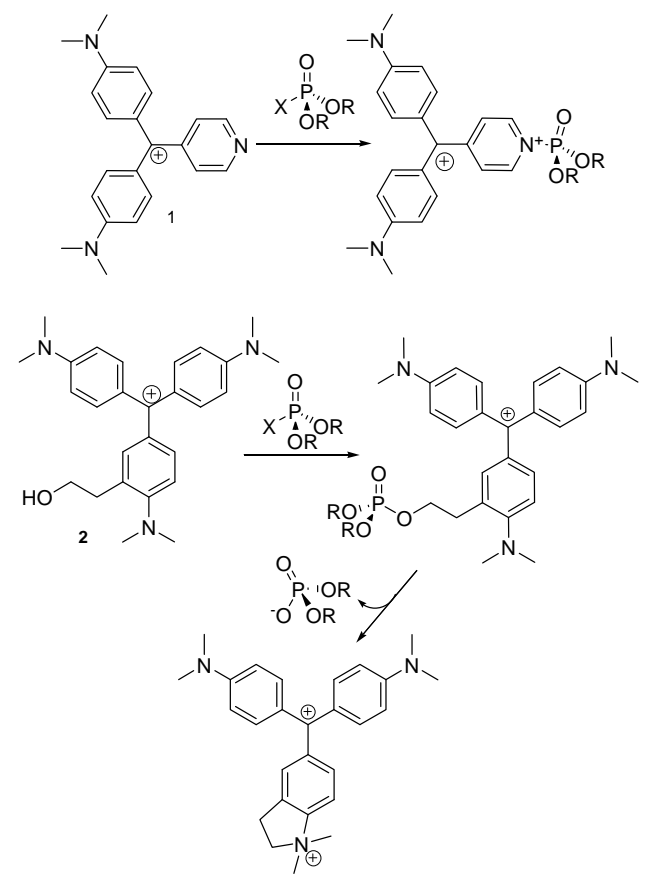

Scheme 2: Reactivity of 1 and 2 with DCP and DCNP 


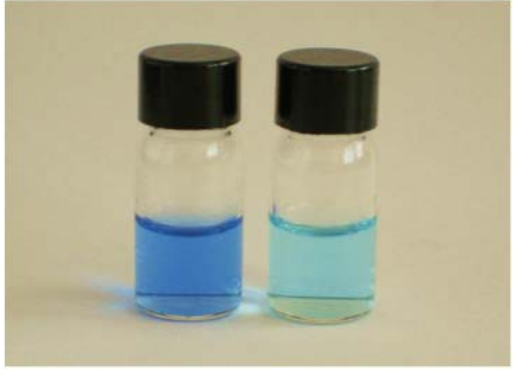

Figure 5: (left) Probe $2\left(1 \times 10-5 \mathrm{~mol} \mathrm{dm}^{-3}\right.$ in buffered acetonitrile:water $(25: 75 \mathrm{v} / \mathrm{v})$ solutions $(\mathrm{pH} \mathrm{5.5}$, MES 0.1 mol $\left.\mathrm{dm}^{-3}\right)$ and (right) 2 (1x10-5 mol dm $\mathrm{dm}^{-3}$ in buffered acetonitrile:water $(25: 75 \mathrm{v} / \mathrm{v})$ solutions $(\mathrm{pH} \mathrm{5.5,} \mathrm{MES} 0.1 \mathrm{~mol}$ $\mathrm{dm}-3)$ ) upon addition of 100 equiv of DCNP. More pronounced colour changes (from marine blue to turquoise) can be perceived on the real sample when compared to the picture.

In order to demonstrate the mechanism involved in the observed chromogenic response, $\mathrm{N}, \mathrm{N}$-dimethylanilino compound was also prepared following a different synthetic path via the reaction of $\mathbf{2}$ with $p$-toluenesulfonyl chloride in the presence of sodium carbonate in acetonitrile. This resulted in the corresponding tosylated derivative that underwent spontaneous cyclisation to give the cyclised product. The formation of this final derivative was easily detected in the ${ }^{1} \mathrm{H}-\mathrm{NMR}$ spectra of the final product; as expected, more marked changes in the signals of dye 2 in the presence of DCNP or DCP were observed for the hydrogen atoms in the five-membered ring; i.e., $\mathrm{H}_{\mathrm{c}}$ was shifted $0.13 \mathrm{ppm}$ downfield whereas $\mathrm{H}_{\mathrm{d}}$ and $\mathrm{H}_{\mathrm{e}}$ were upfield shifted at 0.05 and $0.08 \mathrm{ppm}$, respectively. In addition, very minor or insignificant shift changes were observed for $\mathrm{H}_{\mathrm{f}}$ and $\mathrm{H}_{\mathrm{g}}$.

\section{Selectivity and detection limits}

Other studies also confirmed that 1-2 were unable to react with other organophosphorus derivatives (i.e., OP1-OP4) (see Figure 4) under similar conditions, indicating that the sensing chromogenic reaction was selective for the detection of simulants DCP and DCNP. The detection limits for probes $\mathbf{1}$ and $\mathbf{2}$ were 3.2 x $10^{-3} \mathrm{~mol} \mathrm{dm}^{-3}$ and $2.1 \times 10^{-3} \mathrm{~mol} \mathrm{dm}^{-3}$ for DCP and $8.0 \times 10^{-3}$ mol dm${ }^{-3}$ and $4.1 \times 10^{-3} \mathrm{~mol} \mathrm{dm}^{-3}$ for DCNP, respectively. These values are similar to these obtained with other chemodosimeters based on a similar approaches. ${ }^{21}$

\section{Kinetic studies}

In order to gain a better understanding of the reaction, the reactivity between compounds 1 and 2 and DCP and DCNP in buffered acetonitrile-water $(75: 25 \mathrm{v} / \mathrm{v})$ solutions $(\mathrm{pH} 5.5$, MES $0.1 \mathrm{~mol} \mathrm{dm}^{-3}$ ) was studied. For each probe a battery of experiments were carried out using different concentrations of simulant. These concentrations were always in an excess to considerer pseudo first-order conditions. Monitoring in each case the changes in the absorbance intensity at $655 \mathrm{~nm}$ and $627 \mathrm{~nm}$ for 1 and 2 , respectively, and by plotting $\ln \left[\left(\mathrm{A}_{\mathrm{f}}-\mathrm{A}\right) / \mathrm{A}_{\mathrm{f}}\right]$ versus time (where $\mathrm{A}_{\mathrm{f}}$ was the final absorbance and $\mathrm{A}$ was the absorbance at a given time) allowed us to determine the observed rate constant $\left(k_{o b s}\right)$ for the reaction of the nerve agent simulants with $\mathbf{1}$ and $\mathbf{2 .}$ From these data, the constant rates for the studied reactions were evaluated and from them the corresponding half-life time $\left(\mathrm{t}_{1 / 2}=\right.$ $\ln 2 / k)$ were calculated. Table 1 summarises the results obtained. Additionally, as an example, Figure 6 shows the increase in the absorbance at $627 \mathrm{~nm}$ for dye 2 in the presence of 300 equiv of DCNP in buffered acetonitrile:water 25:75 v/v mixtures.
Table 1. Kinetic data for Ligands 1 and 2

\begin{tabular}{c|cccc}
\hline Ligand & \multicolumn{2}{|c}{$D C P$} & \multicolumn{2}{c}{$D C N P$} \\
\hline & $k\left[\mathrm{~s}^{-1}\right]$ & $\mathrm{t}_{1 / 2}[\mathrm{~s}]$ & $k\left[\mathrm{~s}^{-1}\right]$ & $\mathrm{t}_{1 / 2}[\mathrm{~s}]$ \\
$\mathbf{1}$ & 91.97 & $<0.01$ & 21.74 & 0.03 \\
$\mathbf{2}$ & $>100$ & $<0.01$ & 1.36 & 0.51 \\
\hline
\end{tabular}

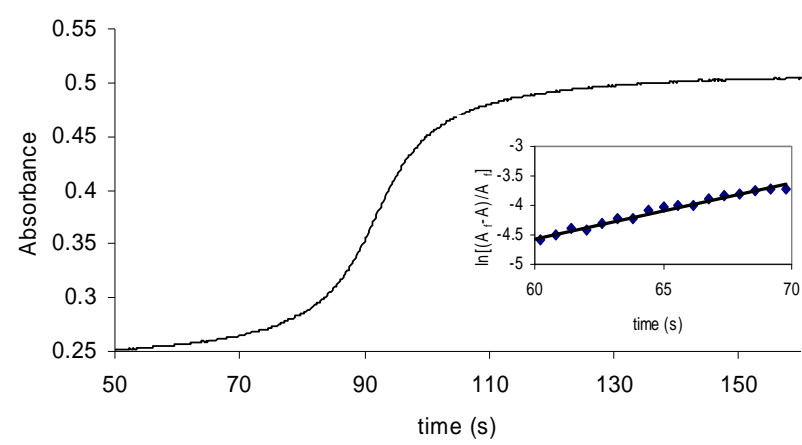

Figure 6: Absorption changes at $627 \mathrm{~nm}$ upon the reaction of 2 with DCNP (300 equiv.). The inset shows the pseudofirst-order kinetic plot achieved after an induction time of $40 \mathrm{~s}$ ).

The rate constants were $0.016 \mathrm{~s}^{-1}$ and $0.001 \mathrm{~s}^{-1}$ for $\mathbf{1}$ in the presence of DCP and DCNP, whereas the $k$ values for 2 were higher; i.e., $0.095 \mathrm{~s}^{-1}$ and $0.035 \mathrm{~s}^{-1}$ for DCP and DCNP, respectively. Regarding the latter probe, in systems which employ similar cyclisation paradigms for the detection of nerve gases simulants, it has been reported that the reaction of alcohol with the phosphorous atom to form the phosphate ester intermediate is slow when compared with intramolecular cyclisation. $^{21}$

\section{Conclusions}

Two new triarylmethyl cations ( $\mathbf{1}$ and $\mathbf{2}$ ) have been reported as probes for the colorimetric sensing of nerve agent simulants. The reaction of 1 with DCP and DCNP results in phosphorylation at the pyridine, which induces a bathochromic shift in the UV-Vis spectrum. Compound 2 also shows a bathochromic shift in the presence of nerve agent stimulants; in this case, however, the phosphorylation of the hydroxyl group was followed by intramolecular cyclisation. In both cases, a modulation in the electronic donor properties of the nitrogen atoms occurs and results in colour changes which can be observed to the naked eye. It is remarkable that chemosensors 1 and $\mathbf{2}$ react only with DCP and DCNP, which show similar chemical structures to the Sarin, Soman and Tabun nerve agents, whereas 1 and 2 remain silent in the presence of other organophosphorous derivatives such as OP1-4. The simple preparation of these derivatives and their selective response make the preparation of other probes using a similar combination of nucleophilic groups (i.e., pyridine and hydroxyl moieties) with different dyes feasible. Further studies in this line are being carried out.

\section{Experimental section}

THF was distilled from $\mathrm{Na}$ /benzophenone under $\mathrm{Ar}$ prior to use. All other reagents were commercially available, and were used without purification. Silica gel $60 \mathrm{~F}_{254}$ (Merck) plates were used for TLC. ${ }^{1} \mathrm{H}-\mathrm{NMR}$ and ${ }^{13} \mathrm{C}$-NMR spectra were recorded on a Bruker $500 \mathrm{MHz}$ spectrometer. Chemical shifts are reported in ppm units with tetramethylsilane as an internal standard. High resolution mass spectra were recorded in the positive ion mode 
on a VG-AutoSpec mass spectrometer. UV-vis absorption spectra were recorded using a $1 \mathrm{~cm}$ path length quartz cuvette on a Shimadzu UV-2101PC spectrophotometer. All measurements were carried out at $293 \mathrm{~K}$ (thermostated).

\section{Synthesis of cations 1 and 2}

The synthesis of $\mathbf{1}$ was carried out following procedures described in the literature, ${ }^{23}$ whereas compound 2 was prepared using the pathway described in Scheme 1. The synthesis involved the use of the previously reported 2-[4-bromo-2-(N,Ndimethylamino)phenyl]ethanol. ${ }^{24,25} 200 \mathrm{mg}(0.82 \mathrm{mmol})$ of bromide was dissolved under argon atmosphere in $8 \mathrm{ml}$ of dry THF. The solution was cooled down to $-78^{\circ} \mathrm{C}$, and then $1.23 \mathrm{ml}$ (1.97 mmol) of a $1.6 \mathrm{M}$ butyl lithium solution was added dropwise. After $15 \mathrm{~min}, 219.37 \mathrm{mg}(0.82 \mathrm{mmol})$ of 4,4'(dimethylamino)benzophenone dissolved in $7 \mathrm{ml}$ of dry THF were added. Reaction was kept overnight. After quenching the remanent butyl lithium with water, the organic solvent was partially removed. The mixture was dissolved in $10 \mathrm{ml}$ of $\mathrm{MeOH}$, and was heated to $50-60{ }^{\circ} \mathrm{C}$ during $20 \mathrm{~min}$ after adding $0.4 \mathrm{ml}$ of a $70 \% \mathrm{HClO}_{4}$ solution. $\mathrm{MeOH}$ was then evaporated, and the remaining oil was partitioned in a $40 \mathrm{ml}$ DCM: $\mathrm{H}_{2} \mathrm{O}$ 1:1 mixture. The aqueous layer was extracted 5 times with portions of $40 \mathrm{ml}$ of DCM, and the combined organic layers were dried with $\mathrm{MgSO}_{4}$. After evaporating the solvent, the product was purified by column chromatography using (DCM to DCM:MeOH, 97:3) as eluent to yield a $34 \%$ of a blue solid. ${ }^{1} \mathrm{H}$ NMR $(500 \mathrm{MHz}$, $\left.\mathrm{CDCl}_{3}\right) \delta 7.35(\mathrm{~d}, \mathrm{~J}=8.6 \mathrm{~Hz}, 4 \mathrm{H}), 7.17(\mathrm{~d}, \mathrm{~J}=2.7 \mathrm{~Hz}, 1 \mathrm{H}), 7.11$ $(\mathrm{dd}, \mathrm{J}=8.5,2.7 \mathrm{~Hz}, 1 \mathrm{H}), 7.00(\mathrm{~d}, \mathrm{~J}=8.5,1 \mathrm{H}), 6,81(\mathrm{~d}, \mathrm{~J}=9.0$ $\mathrm{Hz}, 4 \mathrm{H}) 3.87(\mathrm{t}, \mathrm{J}=6.5, \mathrm{~Hz}, 2 \mathrm{H}), 3.28(\mathrm{~s}, 12 \mathrm{H}), 2.99(\mathrm{~s}, 6 \mathrm{H}), 2.98$ $(\mathrm{t}, \mathrm{J}=6.6 \mathrm{~Hz}, 2 \mathrm{H}) .{ }^{13} \mathrm{C} \mathrm{NMR}\left(75 \mathrm{MHz}, \mathrm{CDCl}_{3}\right) \delta 178.04,158.83$, $156.30,140.54,139.82,135.89,132.04,131.74,127.01,118.35$, $112.99,62.71,44.01,40.71,35.37$. HRMS calcd for $\mathrm{C}_{27} \mathrm{H}_{34} \mathrm{~N}_{3} \mathrm{O}$ $[\mathrm{M}]^{+}: 416.2702$ found 416.2707 .

\section{Acknowledgments}

We thank the Spanish Government (projects MAT2009-14564C01 and MAT2009-14564-C03) and the Generalitat Valenciana (project PROMETEO/2009/016) for support. R. G. is grateful to the Spanish Government for a fellowship. S. R. is grateful to the Generalitat Valenciana for a fellowship. SCSIE (Universidad de Valencia) is gratefully acknowledged for all the equipment employed.

\section{References and notes}

1. Somani, S. M. Chemical Warfare Agents, Academic Press, San Diego, 1992

2. Sadik, O. A.; Land, Jr., W. H.; Wang, J. Electroanalysis 2003, 15, 1149-1159.

3. Eubanks, L. M., Dickerson, T. J.; Janda K. D. Chem. Soc. Rev. 2007, 36, 458-470.
4. Royo, S.; Martínez-Máñez, R.; Sancenón, F.; Costero, A. M.; Parra, M.; Gil, S. Chem. Commun. 2007 4839-4847.

5. Russel, A. J.; Berberich, J. A.; Drevon, G. F.; Koepsel, R. R. Annu. Rev. Biomed. Eng. 2003, 5, 1-27.

6. Wang, H.; Wang, J.; Choi, D.; Tang, Z.; Wu, H.; Lin, Y. Biosens. Bioelectron. 2009, 24, 2377-2383.

7. Steiner, E.; Klopsch, S. J.; English, W. A.; Clowers, B. H.; Hill, H. H. Anal. Chem. 2005, 77, 4792-4799.

8. Khan, M. A. K.; Long, Y. -T.; Schatte, G.; Kraatz, H. -B. Anal. Chem. 2007, 79, 2877-2884.

9. Shulga, O. V.; Palmer, C. Anal. Bioanal. Chem. 2006, 385, 11161123.

10. Zuo, G.; Li, X.; Li, P.; Yang, T.; Wang, Y.; Chen, Z.; Feng, S. Anal. Chim. Acta 2006, 580, 123-126.

11. Zhao, Q.; Zhu, Q.; Shih, W. Y.; Shih, W. -H. Sens. Actuators B 2006, 117, 74-79.

12. He, W.; Liu, Z.; Du, X.; Jiang, Y.; Xiao, D. Talanta 2008, 76, 698-702.

13. Walker, J. P.; Kimble, K. W.; Asher, S. A. Anal. Bioanal. Chem. 2007, 389, 2115-2124.

14. Aernecke, M. J.; Walt, D. R. Sens. Actuators B 2009, 142, 464469.

15. Giordano, B. C.; Collins, G. E. Curr. Org. Chem. 2007, 11, $255-$ 265.

16. Climent, E.; Martí, A.; Royo, S.; Martínez-Máñez, R.; Marcos, M.D.; Sancenón, F.; Soto, J.; Costero, A.M.; Gil, S.; Parra, M. Angew. Chem. Int. Ed. 2010, 49, 5945-5948.

17. Dale, T. J.; Rebek Jr., J. Angew. Chem. Int. Ed. 2009, 48, 78507852 .

18. Weerasinghe A. J.; Schmiesing, C.; Sinn, E. Tetrahedron, 2011, 67, 2833-2838.

19. Wu, X.; Wu, Z.; Han, S. Chem Commun. 2011, 11468-11470.

20. Costero, A. M.; Gil, S.; Parra, M.; Mancini, P. M .E.; MartínezMáñez, R.; Sancenón, F.; Royo, S. Chem. Commun. 2008, 60026004.

21. Costero, A. M.; Parra, M.; Gil, S.; Gotor, R.; Mancini, P. M. E.; Martínez-Máñez, R.; Sancenón, F.; Royo, S. Chem. Asian J. 2010, 5, 1573-1585.

22. Dale, T.J.; Rebek, J. Jr. J. Am. Chem. Soc. 2006, 128, 4500-4501.

23. Bengtsson, G. Acta Chem. Scand. 1964, 18, 447-455.

24. Tanemura, K.; Suzuki, T.; Nishida, Y.; Satsumabayashia, K.; Horaguchi, T. Chem. Commun. 2004, 470-471.

25. Chattise, P. K.; Ramaswamy, A. V.; Waghmode, S. B. Tetrahedron Lett. 2008, 49, 189-194.

26. Cigén, R.; Bengtsson, G. Acta Chem. Scand. 1962, 16, 22512262.

\section{Supplementary Material}

Supplementary material that may be helpful in the review process should be prepared and provided as a separate electronic file. That file can then be transformed into PDF format and submitted along with the manuscript and graphic files to the appropriate editorial office. 